\title{
त्री \\ Lições do mundo-da-vida: o último Husserl e a crítica ao objetivismo
}

\author{
Marcus Sagrini Ayres Ferraz
}

\begin{abstract}
茴
RESUMO

A contraposição da fenomenologia à natureza idealizada da ciência moderna já chegou a alimentar o anticientificismo de muitos. Opondo-se a tal apropriação, neste artigo visa-se recuperar o sentido das observações de Husserl sobre Galileu, inserindo-as na proposta fenomenológica de ampliação da racionalidade.

Palavras-Ghave $\bullet$ Mundo-da-vida. Física matemática. Objetivismo. Fenomenologia. Husserl. Galileu.
\end{abstract}

Num texto explicitamente polêmico, "O processo de Galileu no século xx", Paolo Rossi (cf. 1992) visava combater o ímpeto irracionalista de muitos literatos, jornalistas e filósofos amadores que, no final dos anos sessenta, encantados com as promessas libertárias daquele "clima de cultura" (Rossi, 1992, p. 15), depreciavam as bases da ciência moderna, pensando contribuir para o "advento de uma iminente e purificadora revolução das massas" (1992, p. 10). Muitos críticos do capitalismo não buscavam a raiz da exploração e da desumanização geradas por tal sistema em instituições e modos de organização social sedimentados historicamente, mas nos pressupostos metafísicos da ciência moderna e na sua ênfase no domínio técnico dos fenômenos naturais. Desse modo, a origem dos graves problemas sociais contemporâneos estaria na instauração de uma ciência para a qual o ser humano não é, por um lado, senão um mero espectador da ordem mecânica de um mundo indiferente, e, por outro, reprodutor eficaz de resultados fenomênicos. Daí que os críticos do sistema tenham passado a atacar ferozmente as conquistas da ciência moderna. Acreditavam que ela não só levava à fria desconsideração dos valores éticos e sociais, meras ilusões ante a natureza objetiva, mas também propiciava um controle dos fenômenos que não era sem contrapartida na dominação social do capitalismo. Para Rossi, tais juízos são inaceitáveis. Segundo ele, tais críticos "tendem a liberar-se das responsabilidades de uma crise histórica projetando-a na distância de uma crise cósmica" (1992, p. 23). Contrapondo-se à crise social, 
“a crítica 'global' da técnica e da indústria moderna (...) se dilui numa recusa da ciência e do intelecto" (1992, p. 26), e o impulso revolucionário acaba por se contentar com uma "concepção mágica e animista do mundo". Aliás, Rossi não deixa de frisar que, conquanto tal obscurantismo se disfarçasse de pensamento revolucionário, de fato, "representava apenas o ressurgimento na cultura européia dos velhos temas do arcaísmo, da nostalgia do nada, da tentação do não-humano" (1992, p. 26).

Husserl figura no tétrico painel traçado em $A$ ciência e a filosofia dos modernos como um dos deflagradores do irracionalismo no século xx. Embora, com o distanciamento dos anos, numa "nota prévia", o próprio Rossi tenha admitido que "reformularia de maneira muito diferente as referências à Krisis de Edmund Husserl, sobretudo àquelas páginas que não contêm juízos totalmente aceitáveis" (1992, p. 10), resta a questão de saber por que um racionalista convicto foi tomado como fonte para detratores da razão, e se essa apropriação é legítima. Além do mais, como o próprio Rossi nos lembra que os temas ligados ao anticientificismo "encontram ainda amplo espaço" (1992, p. 11), o que o leva a deixar na nova edição de seu livro a íntegra da inflamada introdução dos anos setenta, cumpre ainda com a maior urgência esclarecer alguns temas da reflexão de Husserl a fim de evitar que os mal-entendidos acerca da fenomenologia no século xx continuem se reproduzindo.

O que levou Rossi a tomar Husserl como propulsor da voga irracionalista dos anos sessenta? Certamente, trata-se da temática do Lebenswelt, "o mundo da experiência pré-dado imediatamente antes de toda operação lógica” (Husserl, 1970a, p. 47; grifos do autor). Husserl opõe tal experiência, na qual tudo se nos apresenta por gradações subjetivo-relativas, à concepção da natureza como conjunto de objetos determináveis em si mesmos. Segundo Husserl, é preciso retornar ao mundo vivido, tal a influência de pré-concepções projetadas sobre a experiência sensível. O mundo-da-vida está oculto pela impregnação dos resultados científicos na vida intuitiva. E mesmo se se ignora os incontáveis resultados das pesquisas científicas, ao menos um princípio difuso coordena a apreensão da experiência perceptiva, aquele segundo o qual a totalidade das coisas é afirmada como suscetível de ser determinada sem resíduo pela ciência. Ingenuamente considera-se, mesmo se de modo impreciso e geral, que "os objetos de nossa experiência são determinados em si, e que a atividade de conhecimento consiste precisamente em descobrir por aproximação essas determinações subsistentes em si, em estabelecê-las 'objetivamente', tal como elas são em si” (1970a, p. 50). Essa tese nasce, para Husserl, da ciência moderna; mais especificamente da obra de Galileu: "a matematização da natureza (...), transformada depois de Galileu no esquema prévio do estudo da natureza em geral, tornou-se tão perfeitamente evidente que já quando da sua instituição o mundo exato substituiu aquele da nossa experiência" (1970a, p. 51). A concepção de uma esfera de objetos determinados em si mesmos, independentes da 
nossa apreensão sensível e tomados como infra-estrutura da experiência acaba por sobrepor-se à vivência intuitiva como a realidade do mundo. Anuncia-se o objetivismo, a pretensão de exprimir verdades independentes das gradações da vida sensível, que é então desvalorizada como instrumento de expressão do real.

O propósito de Husserl com o retorno ao mundo subjetivo-relativo, dimensão aproximativa, sempre referente ao ponto de vista do sujeito, é mostrar que o Lebenswelt "constitui o solo de toda operação de conhecimento e de toda determinação científica" (1970a, p. 48). Qual o sentido desse projeto? Volta a uma concepção mágica do mundo procedente de uma recusa do intelecto? Relativização da ciência por referência a dados psicológicos? Estar-se-ia indo rápido demais se assim se julgasse. Mas também não se pode negar que as afirmações husserlianas, lidas apressadamente, motivam as apropriações irracionalistas que tanto incomodaram Rossi. Para refutá-las, enfim, devemos tornar clara qual é a tarefa do mundo-da-vida no projeto husserliano. Como vimos, ele é contraposto à natureza idealizada, atribuída a Galileu. Esse procedimento nos sugere um caminho de exposição. Recuperaremos, em um primeiro momento, alguns elementos da empreitada galileana, a fim de, em seguida, compreender mais claramente a tematização husserliana do mundo-da-vida e, finalmente, avaliar se tal projeto pode alimentar arroubos obscurantistas.

Galileu é um autor difícil. Há tensões internas à sua obra que impedem de expor seu pensamento como um sistema fechado. Desse modo, diferentes interpretações de sua obra têm enfatizado aspectos particulares em detrimento de outros. ${ }^{\mathbf{1}}$ Não foi diferente com Husserl, que viu em Galileu o responsável pela idealização da natureza, ou seja, sua identificação ao modo de ser dos objetos matemáticos. Antes de expor tal interpretação, vale a pena recensear alguns temas nos textos galileanos que tornam visível a motivação do fenomenólogo, uma vez que ele não se refere a nenhuma obra específica de Galileu.

Em primeiro lugar, gostaríamos de discutir alguns aspectos do papel da matemática na ciência galileana. Um famoso trecho do Ensaiador nos dá boas pistas sobre o tema:

I Como nos lembra Feldhay: "desde o início do século xIX, a historiografia oscilou entre diferentes interpretações do que realmente constituiu o núcleo do projeto galileano. Práticas experimentais, platonismo matemático, método aristotélico ou algum tipo de combinação entre experimento e dedutivismo matemático são somente algumas entre muitas alternativas sugeridas pelos estudiosos no decorrer dos anos a fim de pensar e capturar a essência do empreendimento de Galileu" (Feldhay, 1998, p. 81). 
a filosofia encontra-se escrita neste grande livro que continuamente se abre perante nossos olhos (isto é, o universo), que não se pode compreender antes de entender a língua e conhecer os caracteres com os quais está escrito. Ele está escrito em língua matemática, os caracteres são triângulos, circunferências e outras figuras geométricas, sem cujos meios é impossível entender humanamente as palavras; sem eles nós vagamos perdidos dentro de um obscuro labirinto (1992, p. 38).

A matemática nos é apresentada como o instrumento adequado para decifrar a natureza, compreender a sua organização, sem o qual ficamos restritos ao registro sensível da sucessão de formas percebidas, pelo qual não é possível estabelecer um conhecimento verdadeiro. Compreenderemos melhor essa posição se a contrastarmos ao cânone da ciência então em voga, contra o qual Galileu propunha uma nova abordagem, o aristotelismo.

Em sua Física, Aristóteles apresenta um sistema extremamente bem elaborado, cuja visão de mundo é por demais complexa para ser desenvolvida aqui. Notemos apenas que Aristóteles, em contraposição a Platão, legitima uma ciência do mundo sensível, ao considerar a essência dos objetos físicos (aquilo que deles nos apropriamos em pensamento quando os conhecemos) intrinsecamente ligada à materialidade desses objetos, não devendo mais ser procurada num céu de idéias separado da matéria. Dada a possibilidade de uma física, Aristóteles delimita seu campo de atuação em relação àquele da matemática, tendo em vista a diferença de tratamento dos seus objetos. Segundo ele, “obviamente os corpos físicos possuem superfícies e volumes, linhas e pontos, e esses são os objetos da matemática" (Física, 193b22). Em princípio, poder-se-ia pensar numa identificação dos campos de atuação das duas disciplinas. Porém, há uma grande diferença, que as separa irremediavelmente. A matemática "não trata deles como limites do corpo físico, nem considera os atributos indicados como atributos de tais corpos" (Física, 193b33). Como entender essa afirmação? A física trata dos objetos do mundo sensível, móveis e materiais. Já a matemática trabalha somente com parte dos objetos estudados pela física. Qual parte? As formas dos objetos materiais. Os entes mundanos, compostos de forma e matéria, estão sujeitos à atualização das potencialidades formais até a própria corrupção final. Como a matemática "não envolve movimento" (Física, 194a5), ou seja, não considera as mudanças necessariamente sofridas pelos seres mundanos, suas considerações não envolvem os "atributos do corpo físico", passíveis de corrupção, mas só as formas de tais objetos. "Em pensamento [os atributos dos corpos físicos] são separáveis do movimento" (Física, 193b34), o que torna possível uma reflexão matemática: trata-se de abstrair as formas da inexorável corrupção a que todos os entes materiais estão sujeitos, tomando-as como um tema autônomo de investigação. 
Como conseqüência dessa delimitação das ciências, a matemática não se aplica ao mundo físico, já que aí as formas, no embate contínuo com a resistência da matéria, jamais encontram sua perfeita atualização; ela é um tratamento puramente intelectual daquilo que na natureza não se apresenta com tal perfeição. ${ }^{2}$ Os objetos físicos, sujeitos a mudanças, só permitem um conhecimento qualitativo, e não comportam a precisão matemática. Em suma, a física aristotélica prescinde da matemática. É importante esclarecer, como bem frisa Koyré, que "nenhum aristotélico jamais pôs em dúvida a certeza das proposições ou demonstrações geométricas" (1991, p.167); simplesmente, não admitiram a aplicação da certeza matemática ao mundo sensível, porquanto "a natureza do ser físico é qualitativa e vaga" (1991, p. 168), irredutível à exatidão requerida pela matemática. ${ }^{3}$

A afirmação de Galileu de que somente pela matemática pode-se compreender a natureza deve ser entendida por contraste à concepção aristotélica. Trata-se de reformular os procedimentos científicos da física. Para Aristóteles, os sentidos são considerados um instrumento necessário e suficiente do conhecimento do mundo sensível (com a conseqüência que já vimos: imprecisão no tratamento dos objetos naturais). Já para Galileu, embora necessários para estabelecer conhecimento, os sentidos não conseguem decifrar a organização da natureza, só exprimida verdadeiramente pela linguagem matemática. Fica, assim, clara uma das importantes diferenças metodológicas entre a ciência aristotélica e a galileana. Para a segunda, os sentidos não revelam mais as coisas como são. Afinal, "se a simples aparência deve determinar a essência, é necessário que [aceitemos] que os sóis, as luas e as estrelas observados em água parada e em espelhos, sejam verdadeiros sóis, verdadeiras luas e verdadeiras estrelas" (Galilei, 1992, p. 120). Se apenas os sentidos guiassem a obtenção de conhecimento, não distinguiríamos a aparência e a realidade. A matemática figura então como um instrumento racional que corrige os dados sensíveis, prevenindo-nos das ilusões e permitindo-nos ler corretamente o livro da natureza.

Ao desqualificar os sentidos como fonte última do conhecimento, a matemática passa a ser imprescindível para a compreensão dos fenômenos. Tal como é afirmado no Diálogo, "é forçoso confessar que querer tratar as questões naturais sem a geometria é tentar fazer aquilo que é impossível de ser feito" (Galilei, 2004, p. 284). Ora, a aplicação do instrumental matemático aos problemas físicos implica alguma equivalência,

2 Vale notar que a questão tem nuances complicadoras. Nos Segundos analíticos, Aristóteles reconhece que há disciplinas que tratam do mundo concreto e se servem de demonstrações matemáticas, tais como a astronomia e a harmonia, por exemplo. No entanto, permanece válida sua interdição geral a uma física matematizada, tema que nos interessa aqui.

3 Há aqui, como se vê, razões ontológicas para recusar a aplicação da matemática ao mundo sensível. 
por exemplo, entre as formas ideais da geometria e os objetos mundanos. Essa possibilidade era negada pela física aristotélica, uma vez que, segundo tal concepção, os objetos materiais não têm a perfeição daqueles matemáticos, o que inviabilizaria sua utilização nas questões físicas. Retrucando a um argumento exposto por Salviati no Diálogo, Simplício afirma que "essas sutilezas matemáticas são verdadeiras no abstrato, mas aplicadas à matéria sensível e física não funcionam” (2004, p. 285). Essa afirmação exprime a desconfiança aristotélica em relação ao uso de um instrumental ideal a objetos e situações concretas. Tomemos o exemplo de uma esfera em contato com outra. Idealmente, como a esfera é uma forma na qual todos os pontos do seu traçado estão igualmente distantes do centro, elas devem se tocar em um só ponto, do contrário, nem todos estariam numa exata proporção, não se tratando, portanto, de esferas. Porém, como lembra Simplício, "essa demonstração conclui para as esferas em abstrato; mas não, para as materiais” (2004, p. 288). Ecoa aí a interdição aristotélica da aplicação da matemática ao mundo sensível, bem formulada nas seguintes palavras do mesmo personagem: "não há dúvida de que a imperfeição da matéria faz que as coisas tomadas em concreto não correspondam às consideradas em abstrato" (2004, p. 289). Porém, se a matemática é o instrumental sem o qual não se pode avançar em física, como vimos acima, Galileu deve, de algum modo, supor uma correspondência entre os objetos ideais e os sensíveis. Isso nos é explicado nas palavras de Salviati, que nos apresenta uma analogia entre o cientista e o mercador. Ambos almejam obter resultados pelo cálculo, um, efeitos físicos, e, o outro, a quantidade de bens no mercado, por exemplo.

Assim como, para querer que os cálculos correspondam aos açúcares, às sedas e às lãs, é necessário que o contador leve em conta a tara das caixas, embrulhos e outras embalagens, assim também, quando o filósofo geômetra quer reconhecer em concreto os efeitos demonstrados em abstrato, é necessário que desconte os impedimentos da matéria (Galilei, 2004, p. 289).

Desse modo, pela desconsideração de impedimentos relevantes, a conformidade entre o plano abstrato da matemática e o sensível pode ser estabelecida. Quando Simplício insiste no fato de que na dimensão concreta uma esfera real não toca uma outra esfera ou um plano num só ponto, na verdade ele menciona "uma esfera que não é esfera e um plano que não é plano" (2004, p. 288) e seu raciocínio deveria concluir condicionalmente, uma vez que se houvesse esfera e plano perfeitos, "ainda que materiais", ambos se tocariam em um só ponto. E, inversamente, uma esfera e um plano imperfeitos tocam-se em mais de um ponto "mesmo em abstrato" (2004, p. 289), o que confirma a equivalência entre ambas as dimensões. Assim, embora talvez seja difícil encontrar esferas e planos concretos perfeitos, eles seguiriam, caso existam, as regras 
estabelecidas no nível abstrato da geometria. Não há nenhuma cisão entre as duas dimensões e as imperfeições da matéria não devem nos impedir de asseverar que "aquilo que ocorre no concreto ocorre do mesmo modo no abstrato" (2004, p. 289).

Com efeito, para Galileu a identidade entre objetos matemáticos e físicos pode ser afirmada sem problemas. A aplicação da geometria à matéria dá-se como aquela da aritmética às mercadorias: com precaução para se perceber o que deve ou não ser levado em conta. Assim, o geômetra também deve descontar alguns efeitos da matéria como o mercador o faz com o invólucro das mercadorias ao enumerá-las, o que permite que os princípios geométricos valham para o real tal qual os aritméticos para produtos concretos. Esse procedimento para a aplicação matemática pode ser reencontrado nas Duas novas ciências, numa discussão acerca da resistência das máquinas grandes e pequenas. "Abstraindo de todas as imperfeições da matéria e supondo-a perfeitíssima, inalterável e isenta de toda mudança acidental, sua existência material faz com que a máquina maior (...) mais fraca será" (Galilei, 1988b, p. 10). Vale frisar, no entanto, que aquilo que é descontado no processo de abstração deve ser levado em conta naquele de verificação. "Pois é assim que convém proceder nas ciências que aplicam as demonstrações matemáticas aos fenômenos naturais (...), as quais confirmam com experiências sensíveis seus princípios, que são o fundamento de toda a estrutura ulterior" (1988b, p. 14, ). Assim, por exemplo, para formular o princípio geral da queda dos corpos, desconta-se a resistência do ar. Porém, é preciso considerar esse impedimento para entender porque a experiência nos mostra corpos com pesos diferentes caindo com velocidades diferentes.

Mas o que até então figurava como um cuidado metodológico logo adquire estatuto de definição da matéria, que torna compreensível por que, afinal de contas, pode haver identidade entre formas ideais e objetos sensíveis. "Considerando que suponho que a matéria é inalterável, ou seja, sempre a mesma, é evidente que dela, como de toda afecção eterna e necessária, podem-se produzir demonstrações não menos rigorosas que as demonstrações matemáticas" (Galilei, 1988b, p. 10). Trata-se sem dúvida de uma hipótese ontológica que responde a qualquer objeção aristotélica acerca do caráter imperfeito da matéria e a conseqüente impossibilidade de ela suportar a precisão requerida pelas formas geométricas. $\mathrm{O}$ mundo material deve ser considerado em si mesmo como inalterável e, nesse sentido, pode o rigor que já se encontra no plano geométrico ser aí encontrado. O que aparece como imperfeição deve ser descontado nos cálculos físicos, de modo que as demonstrações eternas da geometria possam ser repetidas quando se considera a invariabilidade da matéria. Como conseqüência, não há porque conceder privilégio às formas regulares da geometria em relação a quaisquer outras que se encontre no mundo sensível. A figura que uma pedra tem ao ser quebrada por um martelo é certamente muito mais complicada de obter que aquela de 
uma esfera e, no entanto, a pedra "a tem perfeitissimamente" (Galilei, 2004, p. 291). Trata-se de um argumento por intensidade: se uma forma extremamente complexa pode ser encontrada na natureza, não há razão para postular que as formas regulares da geometria não possam ser encontradas. Elas também estão presentes no mundo, ainda que, por vezes, tenhamos que descontar algumas imperfeições físicas para considerá-las.

Guardemos o estabelecimento da equivalência entre geometria e objetos físicos apontando para o caráter imutável da própria matéria. Esse será um dos pontos questionados por Husserl. O que significa supor uma tal correspondência entre as formas ideais e os objetos sensíveis? Quais implicações ontológicas de tal metodologia? Antes de responder a essas questões, analisemos um outro ponto que também muito interessará ao fenomenólogo.

Vimos que o instrumental matemático corrige os dados dos sentidos oferecendo uma distinção racional entre aparência e realidade, de modo que os sentidos perdem o papel de instância última do conhecimento. Qual passa a ser então a função exercida pelos dados sensíveis? Vejamos qual será ele ao retomar a doutrina galileana da distinção entre qualidades primárias e secundárias. ${ }^{4}$ Galileu expõe tal doutrina ao discutir a afirmação de que o movimento é causa da sensação de calor. Para ele, essa sensação nada mais é senão efeito de uma certa velocidade do movimento de partículas, "pequeníssimos corpos, com determinadas figuras, movimentados com velocidade enorme" (1992, p. 265). Essa asserção estabelece um rígido corte entre componentes especificamente objetivos da natureza e aqueles subjetivos, conseqüências de múltiplas combinações dos primeiros. Generalizando, Galileu considera que "esses cheiros, sabores, cores, etc., em relação ao sujeito onde nos parece residir, não são outra coisa que puros nomes, mas residem no corpo sensitivo, porque se tiramos o animal, todas as outras qualidades anulam-se completamente" (1992, p. 261). Os conteúdos perceptivos só existem enquanto acolhidos por uma "alma sensitiva" ao esta se relacionar com o mundo; eles não fazem parte das propriedades reais da natureza e não são mais que o resultado de sua organização.

Como caracterizar as propriedades reais da natureza? Galileu não acredita que

nos corpos externos, para excitar em nós os sabores, os cheiros e os sons, seja necessário mais que as grandezas, figuras e multiplicidade de movimentos vagarosos ou rápidos", e que "tirando os ouvidos, as línguas e os narizes, permane-

\footnotetext{
4 Rossi alerta que a doutrina das qualidades primárias e secundárias não é de autoria galileana. Bacon apresentara três anos antes que o Saggiatore de Galileu, em seu Novum organum, "uma doutrina que apresenta notável semelhança com a que é desenvolvida no texto galileano" (1992, p. 184). Independente das discussões sobre sua autoria, trata-se de compreender a sua significação filosófica para a matematização da natureza.
} 
Lições do MUNDo-DA-VidA: o Último Husserl e a Grítica ao obJetivismo

cem os números, as figuras e os movimentos, mas não os cheiros nem os sabores (1992, p. 264).

Eis as qualidades reais da natureza: número, grandeza, figura e movimento, das quais as sensações percebidas são conseqüências de seu arranjo em contato com os sentidos. Por isso, essas últimas recebem o nome de qualidades secundárias. Elas "não possuem outra existência a não ser em nós, não sendo outra coisa senão nome fora de nós" (Galilei, 1992, p. 265). Assim, o mundo é formado por caracteres não desvelados totalmente pelos sentidos, que, limitados à profusão de cores, sabores e cheiros, não conseguem distinguir, com precisão, os elementos essenciais da natureza. Como se vê, Galileu adere a um mecanicismo atomista, que delimita bem claramente as qualidades reais do mundo e os efeitos na experiência sensível. Ante tal concepção, Aristóteles se limitara às qualidades secundárias ao considerar o ser da natureza qualitativo, mutável e imperfeito. Mas, como diz Burtt, "os elementos confusos e não confiáveis na figuração sensorial da natureza são de algum modo efeitos dos próprios sentidos" (Burtt, 1991, p. 67). Têm ainda os sentidos função cognitiva? Sim. Haja vista o uso constante na ciência galileana do experimento. Galileu jamais se contentou com o conhecimento $a$ priori da natureza. As realizações experimentais são parte imprescindível do método científico por ele apresentado, o que marca uma relação estrita entre as qualidades sensíveis e o conhecimento. Galileu admite sem problemas, segundo Burtt, "que são os sentidos que nos oferecem o mundo a ser explicado" (Burtt, 1991, p. 64). Porém, nos experimentos, os sentidos não são mais fonte da verdade, como Aristóteles parecia propor. Se a natureza é em sua essência formada por qualidades que, no geral, escapam à sensibilidade, então o experimento é uma comprovação empírica de uma tentativa racional de descrição da camada primária do mundo. Burtt formula bem o ponto: "o mundo dos sentidos não é sua própria explicação; tal como se apresenta, ele é um código não decifrado, um livro escrito em língua estranha, que deve ser interpretado ou explicado em termos do alfabeto dessa língua" (1991, p. 63). Quer dizer que o conhecimento do mundo sensível não é dado pelos próprios sentidos. A função das qualidades sensíveis, produtos das qualidades primárias apreendidas pela alma sensitiva, é indicar um certo estado de coisas objetivo. Se há calor, então há um certo movimento de partículas, por exemplo. E só pela razão pode-se compreender quais estruturas objetivas correspondem a quais sinais subjetivos. Assim, do ponto de vista do mecanicismo, o uso do experimento confirma ou desconfirma um raciocínio que tenta definir uma configuração de propriedades primárias por sua correlação àquelas secundárias.

Cumpre frisar que a camada objetiva da natureza exprime-se matematicamente. Número, figura, grandeza e movimento, as características dos átomos do mundo, são caracteres que pedem uma decifração matemática. Há aqui uma forte justificativa para 
a aplicação da matemática ao sensível: a ordem concreta aceita os princípios abstratos porque sua infra-estrutura mecânica só pode ser compreendida por relações matemáticas. Assim, a matemática não seria um mero instrumento para a organização classificatória das experiências concretas, e sim o meio privilegiado de acesso à verdade do mundo sensível. 5 Se se consideram as qualidades sensíveis como efeitos de uma infraestrutura mecânica exprimível apenas matematicamente, legitima-se a utilização do instrumental geométrico na física. A matemática teria uma validade objetiva e poderia produzir conhecimentos necessários porque traduziria a infra-estrutura mecânica do mundo. Mas podemos afirmar que essa tese decorre dos textos de Galileu? Por mais tentadora que seja, sinalizando uma resposta sistemática às suas opções teóricas, ela não parece concordar com todos os textos. Afinal, numa carta publicada em Ciência e fé, a necessidade do conhecimento não parece originar-se de uma infra-estrutura mecânica, mas do caráter ideal das leis naturais. Nesse texto, a natureza é "inexorável e imutável e jamais ultrapassando os limites das leis a ela impostas, como aquela que em nada se preocupa se suas recônditas razões e modos de operar estão ou não estão ao alcance da capacidade dos homens" (Galilei, 1988a, p. 49). Desse ponto de vista, o privilégio da matemática não seria tanto o de traduzir a camada das qualidades primárias, mas o de exprimir as leis naturais. Além disso, como vimos, a hipótese de Duas novas ciências era que a matéria era inalterável e eterna, o que permitiria reproduzir os princípios obtidos pela geometria no mundo sensível. Essa tese é compatível com o mecanicismo? Como ela se relaciona com o caráter ideal das leis? Não pretendemos aqui esclarecer problemas que os acurados comentadores de Galileu há tempos discutem. Contentamo-nos em assinalar a assunção do método matemático pela equivalência objetiva do campo abstrato da geometria com aquele dos objetos concretos e a redução das qualidades sensíveis a estados psicológicos, ainda que tais temas não se vinculem claramente como efeito e causa nos textos do autor.

\section{III}

Retornemos finalmente a Husserl para acompanhar sua leitura da matematização da natureza. É importante notar qual tarefa esse tema cumpre no interior de $A$ crise das ciências européias e a fenomenologia transcendental. Husserl está preocupado em recuperar o sentido da empreitada filosófica moderna, que, para ele, é responsável por orga-

5 Burtt nota que “a ordem racional (...) é a única capaz de nos fornecer a explicação desejada. Tal ordem é sempre matemática e só pode ser alcançada através de métodos aceitos da demonstração matemática” (1991, p. 64). 
nizar o conjunto da vida cultural européia (Cf. Husserl, 1970b, §5), e que, por ter sido distorcida na realização da sua motivação original, acaba por alimentar uma crise de toda a civilização ocidental. Tal motivação seria o desenvolvimento de uma ciência da totalidade do ente: “essa nova filosofia não deseja nada menos que englobar na unidade de um sistema teorético todas as questões providas de sentido sem exceção de uma maneira rigorosamente científica, em uma metodologia racional apodítica e em um progresso infinito de investigação" (197ob, §3, p. 13). Seu caráter omni-englobante explica a sua proeminência na vida cultural: todas as questões, incluindo aquelas sobre a eternidade e a imortalidade, seriam passíveis de um tratamento racional, o que propiciaria ordenar um sistema de conhecimentos e de valores que permitiria um convívio social fundamentado em regras absolutas. Uma vez abandonado esse programa, dado o fracasso da metafísica e a tendência positivista pela qual as ciências particulares se limitam a fatos, perde-se o sistema de valores e fins racionalmente estabelecidos, relativizados como tendências históricas ou psicológicas. A meta final de Husserl na Crise das ciências é recuperar o telos proposto para a humanidade com a idéia de filosofia universal, qual seja, "querer ser uma humanidade saída da razão filosófica (...) no movimento infinito no qual a razão passa do latente ao patente" (197ob, §6, p. 21), de modo que os ideais racionais mostrem-se não como particularidades antropológicas do ocidente, mas como aquilo que "está incluído por essência na humanidade como tal" (1970b, §6, p. 21). O método da Crise é uma reflexão histórica que remonta às origens do projeto moderno de filosofia e acompanha as mutações pelas quais a concepção de conhecimento da totalidade dos entes foi realizada, de modo a explicitar o desenvolvimento científico até o insuportável reducionismo positivista. Assim, Husserl pretende esclarecer diversas obscuridades desse processo e propor uma retomada dos ideais absolutos racionais por meio da fenomenologia transcendental. Não trataremos aqui de todo esse projeto; centrar-nos-emos num dos momentos iniciais da transformação da tarefa da filosofia: a invenção de uma física matemática, atribuída por Husserl a Galileu. Cumpre frisar que Husserl reconhece uma certa generalização do problema ao atribuir toda a matematização da física a Galileu. Ele admite estar "simplificando e idealizando de uma certa maneira o estado de coisas" (197ob, §9l, p. 67), o que não invalida suas análises, pois crê que a idéia de uma natureza concreta tomada como "multiplicidade matemática" (1970b, §9, p. 27) foi pela primeira vez estabelecida na obra de Galileu.

O fenomenólogo explicita, primeiramente, o processo de formação da geometria pura, herdada por Galileu. Lembremos que, para Husserl, o mundo circundante comporta gradações em todas as propriedades das coisas percebidas, sempre referidas a um ponto de vista subjetivo; em suma, ele nunca é percebido objetivamente. Porém, as necessidades cotidianas e as melhorias técnicas daí decorrentes levam à busca de 
parâmetros intersubjetivos de acordo. A agrimensura e outras artes de metragem oferecem um acesso comum às formas de corpos intuitivamente dados sem objetividade. Escolhendo "como medidas certas formas empíricas fundamentais, fixadas concretamente a corpos empiricamente constantes e de facto geralmente disponíveis" (197ob, §9a, p. 33), chega-se a um grau relativo de objetivação das aparências percebidas discrepantemente por diferentes sujeitos. A geometria surge como atividade teórica de determinação sistemática das formas ideais para as quais as séries de medidas da agrimensura apontam; e com ela surge um mundo objetivo, ou seja, uma totalidade de objetos (no caso, ideais) cuja determinação vale para todos.

A geometria, motivada em seu desenvolvimento pela agrimensura, logo acaba por dirigir e aperfeiçoar essa técnica, oferecendo um método unívoco para a determinação objetiva de formas, áreas, perímetros etc. Essa aplicação da geometria, conhecida desde a Antigüidade, estende a determinação objetiva do mundo das idealidades àquele da intuição sensível. Mas como isso é possível? Segundo Husserl, a matemática só se refere aos corpos concretos por meio de uma abstração: "ela só se relaciona com as formas abstratas da espaço-temporalidade, e além do mais, a essas somente como formas-limites “ideais"” (1970b, §9b, p. 35). A matemática pode ser aplicada se se considera o caráter formal dos objetos e de suas relações por aproximação a idealidades, desconsiderando as imperfeições da matéria, lembraria Salviati a um atônito Simplício. Obtém-se então um conhecimento indutivo da determinação causal dos eventos.

Graças à matemática pura e à arte prática da medida (...) pode-se 'calcular' cada vez, com base nos dados-da-forma que se possui e que se mediu aqueles que são desconhecidos (...). Assim, a geometria ideal (...) torna-se um método geral para o conhecimento de realidades (1970b, §9b, p. 38).

E para tanto não é preciso supor, como propunha Duas novas ciências, que a matéria do mundo é inalterável assim como o reino das idealidades matemáticas, o que legitimaria o trânsito entre ambos. Basta reconhecer que as coisas do mundo-da-vida têm seus hábitos, "comportam-se de modo semelhante em circunstâncias semelhantes" (197ob, §9b, p. 38), que há um estilo causal do mundo que comporta hipóteses indutivas como as que a aplicação da matemática oferece. Entretanto, o ideal científico de conhecimento total do ente não poderia se contentar com essa vaga noção da unidade da experiência pelo caráter causal de todo evento. A objetivação das formas e dos movimentos por meio da aplicação da matemática sugere a extensão de tal conhecimento "para todas as propriedades reais e todas as relações de causalidade real do mundo da intuição" (1970b, §9b, p. 39). Esse é o passo dado por Galileu: a matematização da natureza concreta em geral. 
A dificuldade patente de conceber uma natureza determinável em todos os seus aspectos segundo os métodos matemáticos de conhecimento consiste na irredutível relatividade das qualidades sensíveis que preenchem concretamente os momentosde-forma dos corpos. No seu caso, as medidas obtidas (mais frio, mais quente etc.) não podem ser aperfeiçoadas em sua exatidão pela referência a idealidades que serviriam de padrões para ordenar os diferentes casos intuídos. "Nós não temos duas mas apenas uma forma universal do mundo: não duas mas apenas uma geometria, i. e., uma para as formas, sem ter uma segunda para os plena [as qualidades sensíveis do mundo]" (1970b, §9c, p. 40), lembra-nos Husserl. Só há objetividade direta quanto às formas dos corpos e suas relações espaço-temporais, idealizáveis e domináveis por construção, o que sugere uma forma geral do mundo, a extensão, "configuração universal de todos os corpos" (1970b, §9c, p. 40), pensados somente em termos de localização e relações matematizáveis. Não há nada semelhante para as qualidades sensíveis. Ocorre então uma matematização indireta: elas passam a ser consideradas como índice de alterações no nível das formas, estabelecendo, desse modo, um laço de causalidade universal na natureza, que em todos os seus aspectos pode ser conhecida matematicamente. É o feito obtido pela distinção entre qualidades primárias e secundárias.

Husserl sugere aqui que devemos compreender a aplicação metódica da matemática aos aspectos formais dos corpos e a consideração do sensível como signo das interações de um substrato compreendido matematicamente como duas faces do mesmo processo de idealização da natureza, que só assim pode ser entendido em sua verdadeira amplitude. Como só o domínio das formas espaço-temporais dos corpos pode ser diretamente matematizado, por referência a idealidades, só nessa camada se estabelece uma apreensão objetiva do mundo, ou seja, uma determinação unívoca do que até então só se apresentava discrepantemente segundo a relatividade dos pontos de vista subjetivos. As qualidades sensíveis são tomadas como indicadores psicológicos de eventos determináveis objetivamente, que passam a valer como uma esfera aquém da relatividade subjetiva. Nesse momento, apartam-se as qualidades sensíveis do ser objetivo, que surge como um em-si delas determinante. E a tarefa da física define-se como a descrição dos eventos dessa esfera objetiva, em relação à qual a vida sensível torna-se secundária. Configura-se assim o objetivismo, investigação que busca "a 'verdade objetiva' desse mundo, o que é válido incondicionalmente para esse mundo aos olhos de todo ser racional, em suma: o que é em-si" (1970b, §14, p. 79-80), ou seja, independente da relatividade da sua manifestação sensível. Não é difícil ver como, por tal definição de objetividade, "mundo-dos-corpos realmente separado e fechado sobre si" (1970b, §10, p. 69), os valores e ideais são reduzidos a certas configurações históricas e antropológicas da vida psicológica, perdendo sua universalidade e necessidade, o que gera, segundo Husserl, a crise da humanidade européia. 
Com Galileu se inicia a sobreposição de uma natureza idealizada ao mundo précientífico, cujo aspecto subjetivo-relativo é circunscrito à esfera psicológica. Logo passou-se a tomar "pelo ser verdadeiro o que é método" (197ob, §9l, p. 60) e a objetividade idealizada do mundo foi tomada, historicamente, como realidade objetiva, apagando o verdadeiro papel do mundo-da-vida. Uma vez estabelecida a idealização da natureza, as qualidades sensíveis são dadas como efeitos de uma camada objetiva e o Lebenswelt recebe o caráter depreciativo de ser resultado psicológico do mundo "real". $\mathrm{O}$ esforço husserliano passa a ser então o de fixar a função do mundo-da-vida como origem de toda objetividade.

Como já frisara Husserl, há um estilo causal do mundo que possibilita as antecipações indutivas científicas. Na verdade, antecipações já são realizadas cotidianamente no mundo-da-vida. "Certamente passou-se da indução cotidiana à indução que segue um método científico, mas isso não muda nada a significação essencial do mundo pré-dado como horizonte de toda indução que tenha um sentido" (1970b, §gh, p. $5^{8-9}$ ). Todas as antecipações fenomênicas científicas remetem ao mundo-da-vida, único que é experimentado por nós, e não a um mundo objetivo aquém do vivido intuitivamente. Essa trivialidade foi mascarada pelas conseqüências ontológicas do método matemático de conhecimento, mas deve ser explicitada pela fenomenologia. "O mundo 'objetivamente verdadeiro', aquele da ciência, é uma formação de grau superior, que tem por fundamento a experiência e o pensamento pré-científicos com suas operações de validade" (1970b, §14, p. 80), insiste Husserl. Não se trata de desmentir nenhum resultado científico, mas somente de descrever as operações de idealização pelas quais se pode obter o conhecimento físico, ressaltando a vivência sensível que torna possível tal trabalho.

Qual é a importância de salientar o caráter originário do mundo-da-vida intuído concretamente em relação à natureza idealizada? Para compreendê-la, devemos salientar alguns aspectos gerais da empreitada fenomenológica. Comenta Moura que

a decisão que está na origem da fenomenologia é oriunda da 'evidência' de que o mais simples dos conteúdos a ser expresso por um nome ou dado a uma intuição já envolve elementos categoriais, já traz consigo relações e, por isso mesmo, não é absolutamente simples (1998, p. 209-10).

Daí decorrem duas conseqüências. Em primeiro lugar, reconhece-se que não há nada não-relativo, separado dos modos de doação fenomênicos pelos quais os objetos necessariamente se dão a conhecer. Qualquer objeto só pode ser dado sob um ponto de vista, que capta apenas algumas das suas infinitas relações com outros objetos de seu horizonte. $\mathrm{O}$ fenômeno não é uma representação psicológica cuja correspondência a 
um objeto exterior atestaria a falsidade ou a verdade, e sim o modo de o objeto se manifestar, ou, em outras palavras, é o objeto no como do seu aparecer, na multiplicidade inesgotável de modos de doação pelos quais necessariamente dele nos aproximamos. ${ }^{6}$ Como conseqüência, as qualidades sensíveis não se encerram na interioridade psicológica; elas se estendem sobre toda a amplitude do mundo percebido como múltiplos fenômenos pelos quais temos acesso às coisas. Para a fenomenologia, "não existe presença sem apresentação através de múltiplos modos de doação, sempre variáveis" (Moura, 1998, p. 204). Desse modo, a objetividade pretendida pela física não pode ser legitimada pelo apelo a uma camada verdadeiramente separada da paisagem sensível, pela qual se poderia apreender $a$ definição verdadeira dos objetos. Não se deve compreender a investigação matemática como circunscrição de uma instância independente da mediação dos aspectos subjetivos pelos quais os objetos aparecem, mas, sugere Husserl, como hipótese advinda da aplicação do instrumental matemático sobre alguns fenômenos. E como gosta de lembrar, "a hipótese permanece apesar da sua confirmação, ainda e sempre uma hipótese" (Husserl, 197ob, §9e, p. 48), submetida a um processo histórico infinito de aproximação ao verdadeiro.

Em segundo lugar, o reconhecimento do inevitável caráter relacional dos dados intuídos implica uma ampliação da racionalidade, encontrada agora até mesmo nas ligações entre os fenômenos. É bem verdade que a oposição husserliana entre mundoda-vida e natureza idealizada dá margem a interpretações que salientem uma separação entre os temas fenomenológicos e a razão científica, sugerindo um irracionalismo. Se o Lebenswelt, mundo da doxa, é o fundamento da ciência, não é difícil tomar seu desvelamento como um golpe obscurantista, retorno à contingência e inexatidão por oposição à ciência fundada sobre bases sólidas. Com efeito, Husserl censura o racionalismo clássico "por esquecer o Lebenswelt, deixando de reconhecer-lhe o seu papel de fundamento do mundo científico" (Moura, 1998, p. 204). Entretanto, essa censura não é feita em favor do irracionalismo. Husserl não escolhe o impreciso mundo da opinião e abandona o exato mundo da razão ao explicitar o Lebenswelt como origem da natureza matematizada. Diluindo as rígidas fronteiras entre doxa e episteme, ele nos alerta para o fato de que "há uma razão latente na doxa" (Kisiel, 1986, p. 37), um logos do mundo estético responsável pelo reenvio expressivo entre os diversos conteúdos da experiência (o que não era possível se se considerasse o sensível somente como efeito de um real que ele apenas indica), e que justamente torna possível o estabelecimento de correlações idealizadas entre os fenômenos. A retirada da vestimenta científica do

6 A fenomenologia "se assentará em uma transparência de princípio dos objetos à representação" (Moura, 1998, p. 217). Assim, a percepção sensível não é uma imagem de um mundo verdadeiramente matemático, mas a manifestação de alguns aspectos do objeto, que podem ser, por meio da idealização comentada, matematizados. 
Lebenswelt não nos condena a um mundo caótico ou mágico. O mundo-da-vida não é antilógico ou anticientífico; é, antes, a pátria de toda atividade racional. Os fenômenos reúnem-se espontaneamente em sistemas de relações, sempre reenviando para os aspectos não dados na intuição atual, constituindo uma rede expressiva. Mesmo "as mais simples percepções de fato que conhecemos (...) versam sobre relações e não sobre termos absolutos" (1945, p. 9; grifos do autor), defende Merleau-Ponty, herdeiro da empreitada de Husserl. Toda figura percebida está imersa num fundo co-visado implicitamente e ao qual a experiência atual reenvia, costurando uma teia de experiências sobre a qual o sujeito elabora posteriormente a reflexão. Os objetos percebidos remetem seja aos seus demais aspectos seja à paisagem co-percebida como temas de novas percepções. Há, destarte, uma organização tácita da experiência sensível segundo uma expressividade natural dos fenômenos. Esse logos sensível não foi notado pelos constituidores da ciência clássica, que preferiram definir os "dados sensíveis" como conseqüência do substrato mecânico estudado matematicamente. A fenomenologia, enfim, não vem restringir o horizonte de racionalidade da contemporaneidade, mas expandi-lo até sua raiz sensível.

Como vimos, a construção da objetividade pelo isolamento das qualidades sensíveis da natureza, tornando-as signos de uma realidade da qual elas não faziam parte, desemboca no objetivismo. Contudo, se não há um aquém do mundo da experiência, já que todo conhecimento deve se manifestar como fenômeno, uma vez afastadas as pretensões de adequação a um "em si”, então se anuncia a recuperação do valor das vivências subjetivas. Esse sem dúvida é um dos principais motivos do retorno ao Lebenswelt. Trata-se de recuperar a dignidade da camada sensível, na qual mesmo a vida ética se desenrola. A psicologização das qualidades secundárias acaba por desvalorizá-las em relação a uma instância anterior, apresentada como objetiva. "Se o mundo dado à intuição, aquele que nós vivemos, é puramente subjetivo, então o conjunto das verdades da vida pré-científica e extracientífica (...) perde seu valor" (Husserl, 197ob, §9i, p. 63). A atividade teórica seria a única que poderia conhecer o mundo verdadeiro; a vida prática seguiria limitada à nuvem opaca de dados sensíveis, sem tocar a essência da natureza. E se é só a ciência que pode compreender o mundo, se, como diz MerleauPonty , "o único ser pensável permanecia definido pelos métodos da ciência" (1945, p. 67), então qualquer verdade relativa à vida prática só aparece quando esta é traduzida matematicamente em um complexo de qualidades objetivas, configurando, assim, o germe do reducionismo que pulveriza a necessidade dos valores humanos, já que esses também são efeitos de uma infra-estrutura material. A recuperação da originariedade do mundo-da-vida circunscreve a atividade teórica da ciência natural como uma atividade no interior do mundo-ambiente, aquela que considera os corpos em sua materialidade, excluídos os predicados valorativos, ou seja, que por um método de empobreci- 
mento pode prever algumas relações entre fenômenos. Porém, no campo originário da atividade humana, acredita Husserl, lidamos com seres e situações valorativamente apreendidos. Diferentes perspectivas de valores visam o mundo de múltiplas maneiras, cada uma com a pretensão de verdade, que, para confirmar sua universalidade, exige o seu reconhecimento pelas demais, configurando assim uma estrutura intersubjetiva sempre em busca do consenso (Cf. Benoist, 1998). Desse modo, Husserl pretende garantir a possibilidade de uma discussão acerca dos valores que embasam a atividade teórica de um ponto de vista não-reducionista.

\section{IV}

Husserl dá o seu próprio diagnóstico da crise da razão ao descrever o processo pelo qual a ciência tende para o objetivismo e do qual a descrição da matematização da natureza acentua uma etapa importante. A proposta de retorno ao Lebenswelt não equivale a um desmentido da ciência e apelo a uma instância mágica salvaguardada do poder destruidor da razão instrumental. Trata-se de parte do projeto de revelar a fonte subjetiva do logos, combatendo o reducionismo positivista e reafirmando a teleologia racional, estabelecida por meio de normas absolutas racionais definidas pela subjetividade transcendental como um aperfeiçoamento infinito do saber e do convívio humano.

Frisemos que Husserl acrescenta ao logos um território até então dele excluído pela ciência matemática, o sensível, cuja teia de reenvios nos apresenta o real em seus múltiplos aspectos, não sendo mais índice de uma realidade distinta, e corrige a distorção ontológica de conceber uma camada não-relativa da experiência do mundo. Ele reconhece que a metafísica objetivista da ciência moderna de fato tem responsabilidade na crise contemporânea. Porém, Paolo Rossi pode permanecer tranqüilo quanto à fenomenologia. Afinal, não se trata, por meio dela, de enfrentar os problemas sociais com um irracionalismo encantado, mas sim de reconduzir a ciência aos trilhos gastos da velha razão universal. ↔

\footnotetext{
Marcus Sagrini Ayres Ferraz

Doutorando do Departamento de Filosofia da Universidade de São Paulo. sacrini@usp.br
} 


\section{ABSTRACT}

The phenomenological opposition to the idealized nature of modern science has already feed the antiscientificism of many. Objecting to such appropriation, in this article one aim at to recover the meaning of Husserl's observations about Galileo, inserting them in the phenomenological proposal of enlargement of the rationality.

KEYwords $\bullet$ Lifeworld. Mathematical physics. Objectivism. Lifeworld. Phenomenology. Husserl. Galileu.

\section{REFERÊNGIAS BIBLIOGRÁFIGAS}

Aristóteles. Physics. In: Ross, D. (Ed.). The works of Aristotle.Oxford, Clarendon Press, 1962. v. 2. (Física).

Benoist, J. O mundo para todos: universalidade e Lebenswelt no último Husserl. Discurso, 29, p. 209-38, 1998.

Burtt, E. As bases metafísicas da ciência moderna. Trad. de J. Viegas Filho \& O. A. Henriques. Brasília, Editora Universidade de Brasília, 1991.

Feldhay, R. The use and abuse of mathematical entities: Galileo and the jesuits revisited. In: Machamer, P. (Ed.). The Cambridge companion to Galileo. Nova Iorque, Cambridge University Press, 1998. p. 80145 .

Galilei, G. Ciência e fé. Cartas sobre a questão religiosa. São Paulo, Nova Stella, 1988a.

. Duas novas ciências. Trad. e notas de L. Mariconda \& P. R. Mariconda. 2a. ed. São Paulo, Ched Editorial/Nova Stella/Istituto Italiano di Cultura, 1988b.

. Il saggiatore. Milão, Feltrinelli, 1992.

. Diálogo sobre os dois máximos sistemas do mundo ptolomaico e copernicano. Trad., introd. e notas de P. R. Mariconda. São Paulo, Discurso Editorial/Imprensa Oficial, 2004.

Husserl, E. Expérience et jugement. Trad. de D. Souche. Paris, PUF, 1970a.

. La crise des sciences européennes et la phénoménologie transcendantale. Trad. de G. Granel. Paris, Gallimard, 197ob.

Kisied, T. J. Phenomenology as the science of science. In: Kockelmans, J. (Ed.). Phenomenology and the natural sciences. Evanston, Northwestern University Press, 1986. p. 5-45.

Kockelmans, J. (Ed.). Phenomenology and the natural sciences. Evanston, Northwestern University Press, 1986.

Koyré, A. Estudos de história do pensamento científico. Trad. de M. L. Menezes. Rio de Janeiro, Forense Universitária, 1991.

Machamer, P. (Ed.). The Cambridge companion to Galileo. Nova Iorque, Cambridge University Press, 1998.

Merleau-Ponty, M. Phénoménologie de la perception. Paris, Gallimard, 1945.

Moura, G. A. R. de. Cartesianismo e fenomenologia: exame de paternidade. Analytica, 3, 1, p. 195-218, 1998.

Ross, D. (Ed.). The works of Aristotle. Oxford, Clarendon Press, 1962.

Rossi, P. A ciência e a filosofia dos modernos. Trad. de A. Lorencini. São Paulo, Editora da Unesp, 1992. 